\title{
EVALUATION OF MODIFIED GLASS IONOMER CEMENTS WITH PROTEIN REPELLENT AND NANOSTRUCTURED ANTIBACTERIAL PROPERTIES IN PREVENTION OF ENAMEL DEMINERALIZATION. AN IN VIVO STUDY
}

\author{
Marwa A. Tawfik* ${ }^{*}$ Rabab Mehesen ${ }^{* *}$ and Tayseer Maaly ${ }^{* * *}$
}

\begin{abstract}
Objectives: To evaluate the in vivo effect of Titanium dioxide (TiO2) nanoparticles and methacryloyloxyethyl phosphoryl choline (MPC) polymer modifications of glass-ionomer cement, to inhibit demineralization around orthodontic bands.

Materials and Methods: 60 orthodontic patients with non-carious molars scheduled for banding were randomly divided into three groups. Grouping was based on (3\% MPC, 3\% nano-Titanium, and $3 \%+3 \%$ of both by weight) added to the luting glass-ionomer cement (GIC) Medicem, which was used for cementation of prefabricated micro-etched orthodontic bands. Demineralization was recorded by using DiagnoDent pen (KaVo, Biberach, Germany) device. Statistical evaluation was performed with one way ANOA test.
\end{abstract}

Results: Bands cemented with conventional GIC showed the highest bacterial scores in comparison to those cemented with MPC polymer and nano-titanium modified GICs. There was significant difference between teeth banded with $3 \% \mathrm{MPC}, 3 \%$ nano-titanium, and $3 \% \mathrm{MPC}+3 \%$ nano-titanium modified GICs.

Conclusions: Modification of the banding GIC with MPC polymer and nano-titanium revealed a positive effect on reducing white spots around orthodontic bands.

KEY WORDS: MPC, Nano-titanium, WSLs, DiagnoDent pen, Orthodontic.

\section{INTRODUCTION}

Dental caries is regarded the most prevalent infectious disease. ${ }^{1}$ Oral biofilms produce acids that could demineralize tooth structure causing caries. ${ }^{2}$ Fixed orthodontic appliances placement make oral hygiene preservation a difficult mission, which leads to the accumulation of biofilm plaque. ${ }^{3}$ White spot lesions (WSLs) on enamel smooth surfaces are caused due to the demineralization which occurs adjacent to the fixed orthodontic appliances. ${ }^{4}$ Mostly, these chalky spots of enamel around appliances can be detected during the follow-up visits, representing the formation of initial lesions. A high incidence of

* Lecturer of Orthodontics, Faculty of Dentistry, Mansoura University.

** Lecturer of Operative Dentistry, Faculty of Dentistry, Mansoura University.

*** Lecturer of Dental Biomaterials, Faculty of Dentistry, Zagazig University 
WSLs has been observed in younger patients with poor oral hygiene during treatment. Different studies have been reported the prevalence of these lesions up to $95 \%$ during fixed orthodontic procedures. ${ }^{5}$ Fluoride therapy, oral health instruction and diet control were combined shown acceptable results for prevention of WSLs. ${ }^{6}$ This combination requires patient cooperation which is not reliable. ${ }^{7}$ The presence of preventive strategies not requiring patient cooperation can greatly be more helpful in this respect. ${ }^{8}$

Glass-ionomer cement (GIC) is widely used for cementing orthodontic bands due to the claims of its anti-cariogenic property by release of fluoride ions. ${ }^{9}$ Recently, methacryloyloxyethyl phosphoryl choline (MPC) polymer can be incorporated into GICs used for banding to act as bacterial-repellent cement. The studies investigated that MPC is a methacrylate with a phospholipid polar group in the side chain ${ }^{10}$, this side chain contain hydrophilic heads and hydrophobic tails. ${ }^{11}$ Once submerged in water, the phospholipids can orient themselves into a bilayer in which the non-polar tails face the inner area of the bilayer, and the polar heads face outward and interact with the water. The protein-repellent polymer surface would reduce biofilm formation, protein adsorption and bacterial adhesion. ${ }^{12}$ It has been incorporated into artificial blood vessels, hip joints, and microfluidic devices. ${ }^{13}$

Nanotechnology has been used in dentistry to enhance mechanical and antibacterial properties of dental materials. ${ }^{14}$ Titanium dioxide (TiO2) nanoparticles are mostly used in medical and in the field of dentistry. ${ }^{15}$

Previous studies showed that $\mathrm{TiO} 2$ nano-particles exhibited significant antimicrobial effects. ${ }^{16}$ Bacteria are less likely to develop resistance against it, so the use of $\mathrm{TiO} 2$ nanoparticles has a good potential for preventing white spot formation. ${ }^{17}$

The introduction of new caries detection devices with the use of traditional instruments, caries can be effectively identified. The non-invasive and quantitative diagnostic laser-based DIAGNOdent pen (KaVo, Biberach, Germany) was evaluated by researchers and dentists in vitro ${ }^{18,19}$ and in vivo studies. ${ }^{20,21}$ This device generates laser light that is absorbed by tooth structure and reflects as fluorescence within the infrared region. This reflected light energy can be quantified and registered as a numerical value. Carious tissue emits stronger fluorescence than sound tissue does; hence, fluorescence from a carious region is greater than that from sound tissue. The origin of fluorescence in carious tissue lies in the porphyrins which produced by oral bacteria. ${ }^{22}$

The addition of MPC to conventional GIC was tried by some researchers, there are not reported in vivo studies. Accordingly, the aims of this in vivo study was to develop protein-repellent, and compare the demineralization preventive effect of conventional GIC and novel multi-functional orthodontic cements modified by incorporating MPC polymer and nano-titanium particles around brackets orthodontic bands cemented by and GIC by using red laser-light induced fluorescence. Our null hypothesis assumed that there were no statistically significant differences by incorporating MPC and nano-Ti filler into GICs.

\section{MATERIALS AND METHODS}

This randomized clinical trial was ethically approved in the Ethics Committee of Faculty of Dentistry, Mansoura University.

The sample of this study consisted of 60 orthodontic patients selected from the clinic of the Orthodontic Department, Faculty of dentistry, Mansoura University. The informed consents were obtained from patients older than 18 and from parents of the younger subjects.

The inclusion criteria were: age ranged from 13 to 20 years, permanent dentition with fully erupted first molars and premolars without visible defects on their buccal and lingual surfaces; and regular tooth-brushing habit.

The patients were examined by two; operative 
and orthodontic; clinicians by visual inspection using a mirror and an explorer. Then the mesial, middle and distal thirds of buccal and lingual surfaces of the teeth were examined using DIAGNOdent pen (Kavo, Biberach, Germany). When both examiners confirmed the absence of WSLs, the patient was included in this study.

This study was designed as a split-mouth design; so that at one side the orthodontic band was cemented by one of the tested material and at the other side the band was cemented by conventional GIC (Medicem, Promedica Dental Material GmbH, Domagkstrasse, Neumuenste, Germany).

The patients were randomly divided into three groups, each group consisted of 20 patients:

Group 1; 3\% MPC + 97\% conventional GIC which used as a control.

Group 2; 3\% nano-titanium particles $+97 \%$ conventional GIC which used as a control.

Group 3; 3\% MPC + 3\% nano-titanium particles $+94 \%$ conventional GIC which used as a control.

Orthodontic bands were placed according to Renfroe $^{23}$. All patients received the same oral hygiene instructions. The upper and the lower bands on both sides were removed after three-months and were examined, evaluated and scored by the operative clinician. After examination the molar bands were reinserted to complete the orthodontic treatment.

At first, the laser devise was calibrated against the device own ceramic standard to ensure an accurate reading, Then, measurements were obtained $1 \mathrm{~mm}$ away from the center of the gingival and occlusal thirds of the buccal and the palatal surfaces of the upper first molar, and $1 \mathrm{~mm}$ away from the center of the gingival and occlusal thirds of the buccal and the lingual surfaces of the lower first molar. The four readings of each tooth were added together and divided by four to obtain the end scores of each molar individually.
The teeth with scores $0-13$ were considered as sound indicating high mineral content and hence clean healthy tooth structure, on the other hand, higher readings as $14-20$ were considered with WSL indicating greater demineralization, and 2129 were considered carious with shallow cavitation (according to DIAGNOdent manual instructions).

\section{DIAGNOdent}

Laser fluorescence measurements were taken with DIAGNOdent pen device using a flat-tip for smooth surfaces. The measurement time was standardized to around $9 \mathrm{sec}$ (as recommended by the manufacturer, the instrument was calibrated against its own supplied ceramic standard before every measurement).

\section{Statistical Analysis:}

The collected data was analyzed using Statistical Package for Social Science software computer program version 23 (SPSS, Inc., Chicago, IL, USA). These data were presented in mean and standard deviation. Student's t-test was used to compare between two different groups while one way analysis of variance (ANOVA) followed by post-hoc tukey test was used for comparing more than two different groups. $P$ value less than 0.05 was considered statistically significant.

\section{RESULTS}

The quantitative DIAGNOdent values and comparisons between the modified cement and conventional cement are shown in (Tables 1, 2, $3)$. Also, the comparison among the different three modified cements are shown in (Table 4). Statistical comparisons showed significant differences between all the modified cements and the control cement $(\mathrm{P}<0.001$ for all groups). The results were plotted in Fig.1. Therefore, the null hypothesis of no statistically significant differences between modified cements and conventional cement was rejected. 


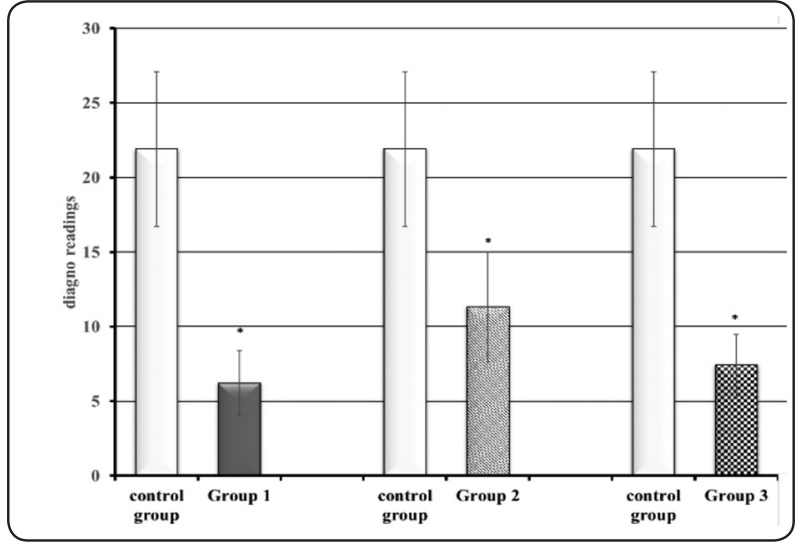

Fig. (1) Comparison of each test group to its control.

TABLE (1) Comparison of MPC modified to conventional GIC.

\begin{tabular}{|c|c|c|c|}
\hline & Control & G 1 & P \\
\hline Score & $21.90 \pm 5.20$ & $6.20 \pm 2.20$ & $<0.001 *$ \\
\hline
\end{tabular}

Data expressed as mean $\pm S D$

TABLE (2) Comparison of NT modified to conventional GIC.

\begin{tabular}{|c|c|c|c|}
\hline & Control & G 2 & P \\
\hline Score & $21.90 \pm 5.2$ & $11.30 \pm 3.68$ & $<0.001^{*}$ \\
\hline
\end{tabular}

Data expressed as mean $\pm S D$

TABLE (3) Comparison of MPC + NT modified to conventional GIC.

\begin{tabular}{|c|c|c|c|}
\hline & Control & G 3 & P \\
\hline Score & $21.90 \pm 5.20$ & $7.40 \pm 4.06$ & $<0.001^{*}$ \\
\hline
\end{tabular}

Data expressed as mean $\pm S D$
Also, there were significant differences among the different three modified cements in inter group comparison. One way ANOVA followed by posthoc tukey test which determined the significance between groups ( 1 and 2 ) and (2 and 3 ). The groups (1 and 3) did not show significant difference. Group 1 showed the lowest DIAGNOdent values and group 2 showed the highest DIAGNOdent values as plotted in Fig.2.

TABLE (4) Comparison among the three test GIC modified groups.

\begin{tabular}{|c|c|c|c|}
\hline & G 1 & G 2 & G 3 \\
\hline score & $6.20 \pm 2.20$ & $11.30 \pm 3.68^{\mathrm{a}}$ & $7.40 \pm 4.06^{\mathrm{b}}$ \\
\hline
\end{tabular}

Data expressed as mean $\pm S D$

a: significance vs to Group $1(p<0.05)$

b: significance vs Group $2(p<0.05)$

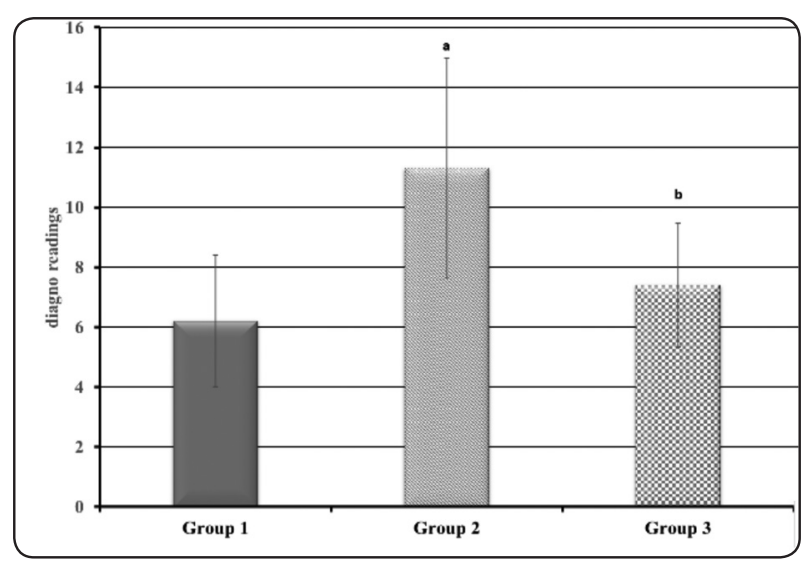

Fig. (2) Comparison among the three test groups.

\section{DISCUSSION}

This study evaluated the effects of novel modified multifunctional glass ionomer cements on the inhibition of enamel demineralization under orthodontic bands, which assessed by the laser fluorescence of enamel lesions with protoporphyrins. DIAGNOdent was used to determine the extent of enamel demineralization. This laser 
device allows for a quantitative method based on the emission of light from a diode laser and the measurement of the reflected fluorescence from the carious tissues. ${ }^{21}$

Mostly, the studies indicated that 50-70\% of teeth restorations were replaced due to failed restorations with secondary caries at the toothrestoration margins. ${ }^{24,25}$ Clinical practice showed that orthodontic banding increases susceptibility of enamel decalcification with its welded attachment as it provides a shelter for plaque accumulation. ${ }^{26}$ Therefore, it is highly desirable to develop proteinrepellent adhesive cements and restorative materials to minimize bacterial attachment and biofilm growth at this weak link. Bacterial adhesion is the first step of biofilm formation, and bacterial adhesion follows protein adsorption onto the enamel, orthodontic appliances, and restorations surfaces. ${ }^{2}$

Various bioactive components: $3 \%$ MPC for protein-repellent capability, 3\% nano-Ti for antibacterial action were incorporated to act as antibacterial defense wall. Recently, MPC polymer and nano-Ti has been widely suggested to prevent the dramatic effect of cariogenic bacteria. In the current study, MPC and nano-Ti were selected as an antibacterial agent, and were easily added to conventional GIC to be used for bands cementation. The results showed that MPC-containing dental cement revealed highest anti-cariogenic effect as MPC polymer is hydrophilic. ${ }^{27}$ It was reported that hydrophilic surfaces are more resistant to protein adsorption than hydrophobic surfaces. ${ }^{28}$ This was confirmed by Zhang $N$ et al when they tried to develop a bioactive orthodontic cement to prevent white spot lesions, and to determine the effects of cement compositions on biofilm growth. ${ }^{29}$

$\mathrm{TiO} 2$ nano-particles are available in varying dimensions and crystalline structures and are recommended as suitable for adding into various dental materials. The results of the present study revealed that $3 \% \mathrm{TiO}_{2}$ nano-particles could reduce caries incidence. This finding was in accordance with previous observations..$^{30,31}$ Regarding to the comparison among the modified groups, it showed that significant difference between MPC and $\mathrm{TiO}_{2}$. This is may be the difference between them in their anti-bacterial effect. This is confirmed by the significant difference between $\mathrm{TiO}_{2}$ and double modification of cement. This double modification of cement did not showed in the third group the highest effect. This is may be due incompatibility between them or incomplete dissolving of MPC polymer in saliva by this combination and this may also have decreased the protein-repellent efficacy. The ratios which was used in our study may need to be modified for better effects. The durability of the protein-repellent capability is an important issue, further studies are needed to incorporate MPC into dental composites to possess the benefit of proteinrepellent and combat secondary caries.

\section{CONCLUSIONS}

- MPC-containing dental materials may be promising to reduce the bacterial adhesion and biofilm formation at orthodontic appliances and the tooth-restoration margins.

- It could be applicable to a wide range of dental bonding agents, cements, sealants and composites.

- Additional studies are required for evaluating the physical properties of this modified GIC, and long term evaluation to their valuable effects.

\section{REFERENCES}

1. Ferracane, JL. Resin composite-State of the art. Dent Mater 2011, 27, 29-38.

2. Eltahlah D, Lynch CD, Chadwick BL, Blum IR, Wilson NHF. An update on the reasons for placement and replacement of direct restorations. J Dent 2018, 72, 1-7.

3. Santamaria MJr, Petermann KD, Vedovello SA, Degan V, Lucato A, Franzini CM. Antimicrobial effect of Melaleuca alternifolia dental gel in orthodontic patients. Am J Orthod Dent Orthop 2014, 145, 198-202. 
4. Behnan SM, Arruda AO, Gonza'lez-Cabezas C, Sohn W, Peters MC. In-vitro evaluation of various treatments to prevent demineralization next to orthodontic brackets. Am J Orthod Dentofacial Orthop. 2010; 138: 712-713.

5. Maxfield BJ, Hamdan AM, Tufekci E, Shroff B, Best AM, Lindauer SJ. Development of white spot lesions during orthodontic treatment: perceptions of patients, parents, orthodontists, and general dentists. Am J Orthod Dentofacial Orthop 2012; 141: 337- 44.

6. Benson PE, Shah AA, Millett DT, Dyer F, Parkin N, Vine RS. Fluorides, orthodontics and demineralization: a systematic review. J Orthod 2005; 32: 102- 14.

7. Kashani M, Farhadi S, Rastegarfard N. Comparison of the effect of three cements on prevention of enamel demineralization adjacent to orthodontic bands. J Dent Res Dent Clin Dent Prospects 2012; 6: 89- 93.

8. Fox NA. Fluoride release from orthodontic bonding materials. An in vitro study. Br J Orthod, 1990; 17: 293-8.

9. Olivia A, Della Ragione F, Salerno A. Biocompatibility studies on glass ionomer cements by primary cultures of human osteoblasts. Biomater 2000; 17:1351-1356.

10. Lewis AL. Phosphoryl choline-based polymers and their use in the prevention of biofouling. Colloids Surf B Biointerfaces 2000; 18: 261-275.

11. Mashaghi S, Jadidi T, Koenderink G, Mashaghi A. Lipid Nanotechnology. Int J Mol Sc. 2013; 14: 4242-4282.

12. Lewis AL, Tolhurst LA, Stratford PW. Analysis of a phosphoryl choline-based polymer coating on a coronary stent pre-and post-implantation. Biomater 2002; 23: 1697-1706.

13. Moro T, Kawaguchi H, Ishihara K, Kyomoto M, Karita T, Ito H. Wear resistance of artificial hip joints with poly (2-methacryloyloxyethyl phosphorylcholine)-graftedpolyethylene: Comparisons with the effect of polyethylene cross-linking and ceramic femoral heads. Biomater 2009; 30: 2995-3001.

14. Ozak ST, Ozkan P. Nanotechnology and dentistry. Eur J Dent 2013; 7:145-51.

15. McINTYRE RA. Common nano-materials and their use in real world applications. Sci Prog 2012; 95:1-22.

16. Kasraei S, Sami L, Hendi S, AliKhani MY, Rezaei-Soufi L, Khamverdi Z. Antibacterial properties of composite resins incorporating silver and zinc oxide nanoparticles on Streptococcus mutans and Lactobacillus. Restor Dent Endod 2014; 39: 109-14.

17. Borzabadi-Farahani A, Borzabadi E, Lynch E. Nanoparticles in orthodontics, a review of antimicrobial and anticaries applications. Acta Odontol Scand 2014; 72: 413-7.
18. Shi XQ, Welander U, Angmar-Mansson B. Occlusal caries detection with KaVo DIAGNOdent and radiography: An in vitro comparison. Caries Res 2000; 34:151-158.

19. Lussi A, Francescut P. Performance of conventional and new methods for the detection of occlusal caries in deciduous teeth. Caries Res 2003; 37:2-7.

20. Attrill DC, Ashley PF. Occlusal caries detection in primary teeth: A comparison of DIAGNOdent with conventional methods. Br Dent J 2001; 190:440-443.

21. Anttonen V, Seppa L, Hausen H. Clinical study of the use of the laser fluorescence device DIAGNOdent for detection of occlusal caries in children. Caries Res 2003; 37:17-23.

22. Hibst R, Paulus R, Lussi A. Detection of occlusal caries by laser fluorescence: basic and clinical investigations. Med Laser Appl 2001; 16: 205 - 213.

23. Renfroe EW. The factor of stabilization in anchorage. Am J Orthod 1956; 42: 883 - 97.

24. Sakaguchi RL. Review of the current status and challenges for dental posterior restorative composites: clinical, chemistry, and physical behavior considerations. Dent Mater 2005; 21:3-6.

25. Sarrett DC. Clinical challenges and the relevance of materials testing for posterior composite restorations. Dent Mater 2005; 21:9-20.

26. Radlanski RJ, Renz H, Reulen A. Distribution of the cement film beneath the orthodontic band: a morphometric in vitro study. J Orofac Orthop 2003; 64:284-292.

27. Katsikogianni M, Missirlis YF. Concise review of mechanisms of bacterial adhesion to biomaterials and of techniques used in estimating bacteria-material interactions. Eur Cells Mater 2004; 8: 37-57.

28. Cheng L, Weir MD, Xu HH, Antonucci JM, Kraigsley AM, Lin NJ, et al. Antibacterial amorphous calcium phosphate nano-composite with quaternary ammonium salt and silver nanoparticles. Dent Mater 2012; 28: 561-572.

29. Zhang N, Melo MSA, Antonucci JM, Lin NJ, Lin-Gibson $\mathrm{S}$, et al. Novel dental cement to combat biofilms and reduce acids for orthodontic applications to avoid enamel demineralization. Mater 2016; 9: 413 - 427.

30. Elsaka SE, Hamouda IM, Swain MV. Titanium dioxide nanoparticles addition to a conventional glass-ionomer restorative: influence on physical and antibacterial properties. J Dent 2011; 39:589-98.

31. Poosti M, Ramazanzadeh B, Zebarjad M, Javadzadeh P, Naderinasab M, Shakeri MT. Shear bond strength and antibacterial effects of orthodontic composite containing $\mathrm{TiO} 2$ nanoparticles. Eur J Orthod 2013; 35:676-9. 